\section{Food for thought: the complex and controversial interaction between diet and physical activity}

\author{
David Hughes
}

\section{THE NUTRITION DIVISION}

At time of writing I am based at the Australian Institute of Sport European Training Centre (ETC) in Gavirate, Northern Italy. The ETC has accommodation for 50 athletes, and during the peak European summer competition phase the adjacent hotel will also be fully occupied with over 100 Australian athletes being accommodated, trained and fed at this northern outpost of Australian highperformance sport. The athletes are in preparation for high-level competition in Europe across a range of sports including rowing, cycling, sailing and canoeing/ kayaking. With important competition imminent, the focus on food is intense, from the nutritional perspective and also from a health/hygiene perspective. Rowing Australia and the Australian Institute of Sport place a heavy emphasis on 'food first', with use of sports supplements being restricted to very specific circumstances in high-performance athletes, under the supervision of appropriately trained Sport and Exercise Medicine (SEM) Physicians and Sports Nutritionists.

One of the stimulating and challenging features of practising SEM is that I often review a subject of which I thought I had a good understanding, only to discover that the literature is inconclusive or a matter of conjecture. One of the key ingredients for improving understanding and knowledge on any topic is robust and open debate. My first foray into SEM was in 1990 when I started the Postgraduate Diploma in Sports Medicine, then based at the London Hospital in Whitechapel. The accepted wisdom in many areas of SEM has altered a great deal since 1990 . A change in thinking regarding any particular SEM topic cannot occur without a willingness to challenge accepted paradigms. One only has to look at issues such as the prescription of footwear, the treatment of concussion, the use of injectable corticosteroids, the recommendations for precompetition and intracompetition

Correspondence to Dr David Hughes, Department of Sports Medicine, Australian Institute of Sport, Bruce, ACT 2617, Australia; david.hughes@ausport.gov.au hydration and the role, or otherwise, of the use of non-steroidal anti-inflammatory medication in the setting of acute injury to see that what was once accepted as gospel can subsequently be considered passé or poor practice.

There is perhaps no area of more sustained interest and robust debate in SEM than the complex interaction between food/nutrition and physical activity. At the community level there is a growing awareness that dietary fats are perhaps not the bogeyman to the extent that has been portrayed in the medical literature and media over the past 30 years. There is increased recognition of the deleterious effects of excessive ingestion of carbohydrate in the Western diet. There has been forthright dialogue between the pro-fat/anticarbohydrate lobby and the anti-fat/procarbohydrate lobby, the dialogue at times being quite energetic. As with all good debates, there are 'fundamentalists' on either side of the great divide. Common sense and experience suggests to me that the truth lies somewhere in between (or perhaps I am just fence-sitting!)

\section{CONSENSUS DEFICIENCY SYNDROME}

In April 2014, BJSM published 'The International Olympic Committee (IOC) Consensus Statement: Beyond the Female Athlete Triad-Relative Energy Deficiency in Sport (RED-S)'. ${ }^{1}$ In this article, the authors proposed the phrase 'Relative Energy Deficiency in Sport' as a broader, more comprehensive term for the condition previously known as 'Female Athlete Triad'. Mountjoy and colleagues suggested that RED-S encompasses a syndrome affecting many aspects of physiological function beyond the triad of energy availability, menstrual dysfunction and bone health. This edition of BJSM sees De Souza et al (see page 1461) refuting the IOC consensus statement, ${ }^{2}$ alleging errors in presenting the physiology of energy deficiency and low-energy availability, the diagnosis of low bone mineral density in adolescents, the effects of oestrogen on bone and calcium and in calcium vitamin $\mathrm{D}$ recommendations. To have two groups of world renowned experts appearing significantly at odds with each other on the important issue of nutritional deficiency in athletes makes for intriguing reading and no doubt the debate will continue beyond this publication.

\section{FOOD AND PHYSICAL ACTIVITY—A POTENT MIX}

All Western countries are directing resources to try and 'turn around the oil tanker' that is childhood obesity. There is abundant evidence in the medical literature of the relationship between physical inactivity, childhood obesity and risk of premature of cardiovascular and joint degenerative disease. Adding to the evidence is the study in this edition by Mathias Ried-Larsen and colleagues (see page 1502) suggesting that a high volume of vigorous physical activity across childhood is independently associated with lower metabolic cardiovascular disease risk in adolescence. There has long been conjecture, however, as to whether or not there is an increased risk of acute musculoskeletal injury among overweight and obese children. Jespersen and colleagues (see page 1497) examined 632 schoolchildren and determined BMI total body fat percentage (TBF\%) using whole-body dual energy X-ray absorptiometry scans. Children determined overweight by BMI and TBF were more at risk of sustaining lower extremity injuries, with TBF being the most accurate indicator, possibly because it also reflects lower relative lean body mass.

In a nice illustration of a medical 'Catch-22' scenario, it seems that not only are children who are obese more at risk of injury, but injury itself actually initiates unfavourable weight gain and obesity markers in young people. A prospective longitudinal study of 862 female soccer and basketball players found that those who sustained a significant knee injury were at risk of unhealthy gain in body mass and detrimental changes in body composition (see page 1477).

Not all benefits of physical activity in overweight and obese individuals relate to physical change or body composition parameters. A 6-month programme of resistance training in overweight and obese adolescent men resulted in statistically significant improvements in selfesteem and exercise efficacy without significant changes in body composition (see page 1482). As with many artificial research interventions, the significant health gains returned to baseline within 6 months of the cessation of intervention.

The American College of Sports Medicine recommends that most adults engage in moderate-intensity cardiorespiratory exercise 
training for $\geq 30 \mathrm{~min} /$ day on $\geq 5$ days/week for a total of $\geq 150 \mathrm{~min} / \mathrm{week}$, vigorousintensity cardiorespiratory exercise training for $\geq 20 \mathrm{~min} /$ day on $\geq 3$ days/week ( $\geq 75 \mathrm{~min} /$ week). ${ }^{3}$ The HUNT study is a longitudinal population health study in Norway with a database about approximately 120000 people that integrates family data and individual data and can be linked to national health registries. It is one of the largest health studies ever performed. ${ }^{4}$ Moholdt et al used the data from the HUNT Study to assess the efficacy of the ACSM recommendations (see page 1489). They concluded that some weight gain throughout life appears to be inevitable and that the current recommendations are not sufficient to prevent weight gain. There was an inverse dose-response relationship between weekly physical activity and weight gain with those who exceeded the current recommendations gaining the least amount of weight.

\section{WHAT'S NEXT ON THE MENU?}

In the community environment and the high-performance sport arena, an understanding of the role of nutrition and its relationship to physiological health and sports performance has been and will remain a complex and evolving area of knowledge. There are many talented individuals around the world who have dedicated their professional lives in understanding how our diet impacts on our physical health and our capacity for exercise. Not all of these talented individuals, however, have drawn the same conclusions. At the patient-practitioner interface, it is crucial that SEM clinicians look for the common threads that span the divide and allow us to give our patients evidence-based advice to improve their quality of life and/or to achieve their exercise performance goals. Food for thought.

Dr David Hughes Chief Medical Officer, Australian Institute of Sport Vice-President, Australasian College of Sports Physicians Medical Director, Australian Olympic Team, Rio 2016

Competing interests None.

Provenance and peer review Commissioned; internally peer reviewed.

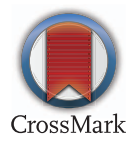

To cite Hughes D. Br J Sports Med 2014;48:14591460.

Accepted 9 July 2014

Br J Sports Med 2014;48:1459-1460.

doi:10.1136/bjsports-2014-094024

\section{REFERENCES}

1 Mountjoy M, Sundgot-Borgen J, Burke L, et al. The IOC consensus statement: beyond the female athlete triad-relative energy deficiency in sport (RED-S). Br J Sports Med 2014;48:491-7.

2 De Souza MJ, Nattiv A, Joy E, et al. 2014 Female Athlete Triad Coalition Consensus Statement on treatment and return to play of the female athlete triad: 1st International Conference held in San Francisco, California, May 2012 and 2nd International Conference held in Indianapolis, Indiana, May 2013. Br J Sports Med 2014;48:289.

3 Garber CE, Blissmer B, Deschenes MR, et al. Quantity and quality of exercise for developing and maintaining cardiorespiratory, musculoskeletal, and neuromotor fitness in apparently healthy adults: guidance for prescribing exercise. Med Sci Sports Exerc 2011;43:1334-59.

4 The HUNT study. A longitudinal population health study in Norway. http://www.ntnu.edu/hunt (accessed 7 Jul 2014). 